\title{
Commentary: Spatiotemporal Modeling of the Key Migratory Events During the Initiation of Adaptive Immunity
}

\author{
Johannes U. Mayer* \\ Malaghan Institute of Medical Research, Wellington, New Zealand
}

Keywords: cell migration, dendritic cells, adaptive immunity, innate immunity, cell tracking, Kaede mice, photoconversion

\section{A Commentary on}

Spatiotemporal Modeling of the Key Migratory Events During the Initiation of Adaptive Immunity

OPEN ACCESS

Edited by:

Luisa Martinez-Pomares,

University of Nottingham,

United Kingdom

Reviewed by:

Vuk Cerovic,

RWTH Aachen University, Germany

Behazine Combadiere,

Institut National de la Santé et de la

Recherche

Médicale (INSERM), France

*Correspondence:

Johannes U. Mayer jmayer@malaghan.org.nz

Specialty section:

This article was submitted to Antigen Presenting Cell Biology,

a section of the journal

Frontiers in Immunology

Received: 01 May 2019 Accepted: 12 September 2019 Published: 24 September 2019

Citation:

Mayer JU (2019) Commentary: Spatiotemporal Modeling of the Key Migratory Events During the Initiation of Adaptive Immunity.

Front. Immunol. 10:2311. doi: 10.3389/fimmu.2019.02311 by Hayes, A. J., Rane, S., Scales, H. E., Meehan, G. R., Benson, R. A., Maroof, A., et al. (2019). Front. Immunol. 10:598. doi: 10.3389/fimmu.2019.00598

The priming of adaptive immune responses in the draining lymph node is a crucial step to initiate functional $\mathrm{T}$ and $\mathrm{B}$ cell responses against newly encountered antigens present in the periphery. While lymph node resident antigen-presenting cells have been reported to present free draining antigen that is transported by lymph and accumulates within the subcapsular sinus shortly after immunization (1-3), the majority of cells that migrate from the tissue to the lymph node arrive after $24 \mathrm{~h}$. A large proportion consists of different populations of conventional dendritic cells, which migrate through the lymphatics to transport antigen from the periphery to the lymph node where they present antigen peptides to naïve T cells to initiate adaptive immunity [recently reviewed in Worbs et al. (4) and Randolph et al. (5)]. However, antigen positive neutrophils, monocyte derived dendritic cells, and monocytes have also been identified in the lymph node under certain conditions (6-9), but defining their migration kinetics and origin remains challenging.

To gain a better understanding of the key migratory events that are elicited by Alum/LPS, a model for Alum-based vaccine administration, Hayes et al. performed a detailed analysis of the cell migration kinetics and antigen presentation events in the draining lymph nodes after footpad immunization (10). Only a limited number of tools are available to monitor the dynamic migration events that occur during an immune response in vivo, with each tool presenting their own advantages, challenges, and limitations.

While two-photon microscopy allows for in vivo imaging in real time, it requires a challenging experimental setup when inner tissues are studied and limits the observation to the fluorescent cell types that can be visualized using reporter mouse strains $(11,12)$.

A more unbiased approach is achieved by cannulating the lymphatic vessels and collecting lymph ex vivo. While small amounts of lymph can be collected via a glass capillary from many locations we can only gain insights into its temporal composition (11). Access to large lymphatic vessels is necessary for the cannulation and continuous collection of lymph. This procedure has been successfully performed for thoracic duct cannulations in mice and rats and allows for the direct assessment of lymph migratory cell populations at steady state and after intestinal immunization (12-14). However, migrating cell populations from other tissues are harder to assess 
as the smaller diameter and sequential positioning of lymph nodes along smaller lymphatic vessels makes the insertion of a cannula at the right location challenging (15).

With the development of photoconvertible fluorescent proteins (namely mEosFP, tdEosFP, Dendra, Dronpa, Kaede, KikGR, and mOrange) and the availability of transgenic mouse strains that either ubiquitously or selectively express these proteins in all cells or certain cell types or organelles (16), tissues of interest can now be photoconverted and migrating cell populations tracked to non-converted tissues.

To conduct a successful photoconversion experiment in vivo, several important details need to be considered:

A) An appropriate light source needs to be chosen that emits the optimal wavelength to photoconvert the fluorescent protein, allows for deep penetration into the tissue to ensure complete photoconversion, and does not cause damage, cell activation or inflammatory reactions that could cause unspecific cell migration.

B) The selection of the experimental model and the cell types studied need to ensure that a distinct photoconverted signature can be detected when cells are collected and that the fluorescent signal is not diluted due to cellular degradation of the photoconverted protein or excessive cell division.

C) The timing of the photoconversion needs to take into account that only cells present at this specific timepoint will be photoconverted, while cells that have already migrated away or subsequently arrive in the tissue will not be distinguishable from non-migrating cells.

When these parameters are appropriately selected, photoconvertible mouse strains are an easy-to-use and flexible option to study the migration kinetics of immune cells at steady state or in response to immunization.

Using ubiquitously expressing Kaede mice, the migration of dendritic cell subsets from the skin and intestine has been well-characterized and were found to be the only tissue migrating immune cell that migrates from the tissue to the lymph node via the lymphatics under steady state conditions (17-19). To study cellular migration during an immune response a large variety of models have been used that range from inducing unspecific inflammation through tape-stripping, the epicutaneous application of irritants or cell labeling dyes, to the subcutaneous or intradermal injection of dyes, adjuvanted proteins, nanoparticles, or pathogens.

To better define the phenotype and kinetics of skin migrating cells after Alum/LPS treatment, Hayes et al. treated photoconvertible Kaede mice with Alum/LPS and tracked the photoconverted cells from the site of treatment to the draining lymph node (10). By combining data from lymph nodes collected at different time points after photoconversion and immunization and modeling the resulting cell migration kinetics mathematically, the authors conclude that migratory cell populations first accumulate in the footpad after Alum/LPS treatment, migrate to the lymph node at a fixed rate and remain in the lymph node for a prolonged period of time compared to the administration of saline (10). While previous studies show that migrating dendritic cells are first detected $3-8 \mathrm{~h}$ after egress from the skin $(20,21)$, Hayes et al. show here that the majority of dendritic cells that accumulate in the lymph node after Alum/LPS treatment accumulate in the tissue $8-12 \mathrm{~h}$ after immunization and migrate to the lymph node at a peak time of $24-36 \mathrm{~h}$ (10). In contrast to other models that use tape stripping or deliver non-adjuvanted antigens by injection $(13,20,22)$, the current study further indicates that the majority of migrating immune cells are not already present in the tissue, but first need to be recruited to the skin after Alum/LPS treatment (10).

While it is assumed that depot formation and the slow release of antigen or inflammatory mediators are responsible for the adjuvanticity of alum (and could explain the accumulation of immune cells), the same laboratory has shown that both alum and CpG induced similar uptake of antigen in the lymph node, regardless of depot formation (23). This suggests that the majority of migrating cells that migrate after Alum/LPS treatment are recruited from outside the tissue and poses the question if the identified population of dendritic cells are indeed conventional tissue-resident dendritic cells. Alternatively, monocyte derived dendritic cells, which accumulate at the site of immunization, have been reported after alum treatment (9), and can express similar levels of MHCII and CD11c after activation (24) could have been reported in this study. It therefore remains to be determined if the migrating dendritic cells observed here are monocyte derived dendritic cells (10), or if they represent conventional dendritic cells that have developed from rapidly arriving dendritic cell progenitors as recently reported for viral infections (25). If identified as monocyte derived dendritic cells, this study would be the first to provide formal evidence that monocyte derived dendritic cells can migrate from the inflamed tissue to the draining lymph nodes via the lymphatics, and do not enter the lymph node via the bloodstream, as currently believed (26).

This would suggest that a therapeutic intervention or targeting of migrating cell populations after Alum/LPS treatment or Alum-based vaccinations should be delayed to account for their accumulation in the tissue and could be developed as an effective tool to influence the outcome of adaptive immune responses in the lymph node.

\section{AUTHOR CONTRIBUTIONS}

The author confirms being the sole contributor of this work and has approved it for publication.

\section{ACKNOWLEDGMENTS}

I would like to thank Prof. Franca Ronchese for providing comments on the manuscript and the Research for Life Foundation for funding. 


\section{REFERENCES}

1. Gerner MY, Casey KA, Kastenmuller W, Germain RN. Dendritic cell and antigen dispersal landscapes regulate T cell immunity. J Exp Med. (2017) 214:3105-22. doi: 10.1084/jem.20170335

2. Allenspach EJ, Lemos MP, Porrett PM, Turka LA, Laufer TM. Migratory and lymphoid-resident dendritic cells cooperate to efficiently prime naive CD4 T cells. Immunity. (2008) 29:795-806. doi: 10.1016/j.immuni.2008.08.013

3. Bernhard CA, Ried C, Kochanek S, Brocker T. CD169+ macrophages are sufficient for priming of CTLs with specificities left out by crosspriming dendritic cells. Proc Natl Acad Sci USA. (2015) 112:5461-6. doi: $10.1073 /$ pnas. 1423356112

4. Worbs T, Hammerschmidt SI, Förster R. Dendritic cell migration in health and disease. Nat Rev Immunol. (2017) 17:30-48. doi: 10.1038/nri.2016.116

5. Randolph GJ, Ivanov S, Zinselmeyer BH, Scallan JP. The lymphatic system: integral roles in immunity. Annu Rev Immunol. (2017) 35:31-52. doi: 10.1146/annurev-immunol-041015-055354

6. Chtanova T, Schaeffer M, Han S-J, van Dooren GG, Nollmann M, Herzmark P, et al. Dynamics of neutrophil migration in lymph nodes during infection. Immunity. (2008) 29:487-96. doi: 10.1016/j.immuni.2008. 07.012

7. Calabro S, Tortoli M, Baudner BC, Pacitto A, Cortese M, O'Hagan DT, et al. Vaccine adjuvants alum and MF59 induce rapid recruitment of neutrophils and monocytes that participate in antigen transport to draining lymph nodes. Vaccine. (2011) 29:1812-23. doi: 10.1016/j.vaccine.2010. 12.090

8. Blecher-Gonen R, Bost P, Hilligan KL, David E, Salame TM, Roussel E, et al. Single-cell analysis of diverse pathogen responses defines a molecular roadmap for generating antigen-specific immunity. Cell Syst. (2019) 8:10921.e6. doi: $10.1016 /$ j.cels.2019.01.001

9. Kool M, Soullie T, van Nimwegen M, Willart MAM, Muskens F, Jung $S$, et al. Alum adjuvant boosts adaptive immunity by inducing uric acid and activating inflammatory dendritic cells. J Exp Med. (2008) 205:869-82. doi: $10.1084 /$ jem. 20071087

10. Hayes AJ, Rane S, Scales HE, Meehan GR, Benson RA, Maroof A, et al. Spatiotemporal modeling of the key migratory events during the initiation of adaptive immunity. Front Immunol. (2019) 10:598. doi: 10.3389/fimmu. 2019.00598

11. Schulz O, Jaensson E, Persson EK, Liu X, Worbs T, Agace WW, et al. Intestinal $\mathrm{CD} 103+$, but not $\mathrm{CX} 3 \mathrm{CR} 1+$, antigen sampling cells migrate in lymph and serve classical dendritic cell functions. J Exp Med. (2009) 206:3101-14. doi: 10.1084/jem.20091925

12. Cerovic V, Houston SA, Scott CL, Aumeunier A, Yrlid U, Mowat AM, et al. Intestinal CD103(-) dendritic cells migrate in lymph and prime effector $\mathrm{T}$ cells. Mucosal Immunol. (2013) 6:104-13. doi: 10.1038/mi.2012.53

13. Mayer JU, Demiri M, Agace WW, MacDonald AS, Svensson-Frej M, Milling SW. Different populations of CD11b+ dendritic cells drive Th2 responses in the small intestine and colon. Nat Commun. (2017) 8:15820. doi: 10.1038/ncomms 15820

14. Bravo-Blas A, Utriainen L, Clay SL, Kästele V, Cerovic V, Cunningham AF, et al. Salmonella enterica Serovar Typhimurium travels to mesenteric lymph nodes both with host cells and autonomously. J Immunol. (2019) 202:260-7. doi: 10.4049/jimmunol.1701254
15. Harrell MI, Iritani BM, Ruddell A. Lymph node mapping in the mouse. $J$ Immunol Methods. (2008) 332:170-4. doi: 10.1016/j.jim.2007.11.012

16. Nemet I, Ropelewski P, Imanishi Y. Applications of phototransformable fluorescent proteins for tracking the dynamics of cellular components. Photochem Photobiol Sci. (2015) 14:1787-806. doi: 10.1039/c5pp00174a

17. Tomura M, Yoshida N, Tanaka J, Karasawa S, Miwa Y, Miyawaki A, et al. Monitoring cellular movement in vivo with photoconvertible fluorescence protein "Kaede" transgenic mice. Proc Natl Acad Sci USA. (2008) 105:10871-6. doi: 10.1073/pnas.0802278105

18. Houston SA, Cerovic V, Thomson C, Brewer J, Mowat AM, Milling S. The lymph nodes draining the small intestine and colon are anatomically separate and immunologically distinct. Mucosal Immunol. (2016) 9:468-78. doi: $10.1038 / \mathrm{mi} .2015 .77$

19. Cerovic V, Bain CC, Mowat AM, Milling SWF. Intestinal macrophages and dendritic cells: what's the difference? Trends Immunol. (2014) 35:270-7. doi: $10.1016 /$ j.it.2014.04.003

20. Tomura M, Hata A, Matsuoka S, Shand FHW, Nakanishi Y, Ikebuchi $\mathrm{R}$, et al. Tracking and quantification of dendritic cell migration and antigen trafficking between the skin and lymph nodes. Sci Rep. (2014) 4:6030. doi: $10.1038 /$ srep06030

21. Garg S, Oran A, Wajchman J, Sasaki S, Maris CH, Kapp JA, et al. Genetic tagging shows increased frequency and longevity of antigenpresenting, skin-derived dendritic cells in vivo. Nat Immunol. (2003) 4:90712. doi: $10.1038 /$ ni962

22. Ruedl C, Koebel P, Bachmann M, Hess M, Karjalainen K. Anatomical origin of dendritic cells determines their life span in peripheral lymph nodes. $J$ Immunol. (2000) 165:4910-16. doi: 10.4049/jimmunol.165.9.4910

23. Hutchison S, Benson RA, Gibson VB, Pollock AH, Garside P, Brewer JM. Antigen depot is not required for alum adjuvanticity. FASEB J. (2012) 26:1272-9. doi: 10.1096/fj.11-184556

24. Chow KV, Lew AM, Sutherland RM, Zhan Y. Monocyte-derived dendritic cells promote Th polarization, whereas conventional dendritic cells promote Th proliferation. J Immunol. (2016) 196:624-36. doi: 10.4049/jimmunol.1501202

25. Cabeza-Cabrerizo M, van Blijswijk J, Wienert S, Heim D, Jenkins RP, Chakravarty P, et al. Tissue clonality of dendritic cell subsets and emergency DCpoiesis revealed by multicolor fate mapping of DC progenitors. Sci Immunol. (2019) 4:eaaw1941. doi: 10.1126/sciimmunol.aaw1941

26. Palframan RT, Jung S, Cheng G, Weninger W, Luo Y, Dorf M, et al. Inflammatory chemokine transport and presentation in HEV: a remote control mechanism for monocyte recruitment to lymph nodes in inflamed tissues. J Exp Med. (2001) 194:1361-73. doi: 10.1084/jem.194.9.1361

Conflict of Interest: The author declares that the research was conducted in the absence of any commercial or financial relationships that could be construed as a potential conflict of interest.

Copyright (C) 2019 Mayer. This is an open-access article distributed under the terms of the Creative Commons Attribution License (CC BY). The use, distribution or reproduction in other forums is permitted, provided the original author(s) and the copyright owner(s) are credited and that the original publication in this journal is cited, in accordance with accepted academic practice. No use, distribution or reproduction is permitted which does not comply with these terms. 